\title{
Morfinomanía y defensa social
}

RESUMEN: Se presenta un caso de morfinomanía de principios de siglo, con el objeto de analizar la larga pugna entre dos saberes disciplinarios -psicopatología y criminología- por la apropiación de un campo entonces naciente en la Argentina, el de las toxicomanías.

PALABRAS CLAVE: historia-toxicomanías-Argentina

A principios de 1923, el diputado Leopoldo Bard solicita al jefe de policía de la capital, Jacinto Fernández, los antecedentes que se hayan podido recoger sobre problemas legales relacionados con el uso de drogas. Su fin era utilizarlos en la elaboración de un proyecto de ley para la represión del abuso de los alcaloides. El 29 de mayo del mismo año Fernández responde al pedido remitiendo un memorándum sobre el primer caso grave sucedido en nuestro país, transcripto del auto de prisión preventiva de N.N., dictado por el juez de instruccióón Arturo L. Domínguez. He elegido trabajar este caso porque, a mi entender, es una rara muestra de eso que Edoardo Grendi denominó "lo excepcional normal"(1) y que Giovanni Levi conceptualiza como el hecho mínimo e individual que revela, sin embargo, fenómenos más generales (2). Mi intención es mostrar a través de este ejemplo la larga pugna entre dos saberes disciplinarios -psicopatología y criminología- por la apropiación de un campo entonces naciente, el de las toxicomanías. Sin desconocer el peso del contexto político en
ABSTRACT: A case of morphinism dated in the beginning of the XXth century is used to illustrate the long fight between two disciplines -criminology and psychopathology- over drug addiction, a newly born area of knowledge in Argentina at the time.

KEY WORDS: history-narcotic addictionArgentina

la construcción estatal de las instituciones y de las prácticas de la medicina mental, me limitaré a abordar este trabajo casi exclusivamente desde la perspectiva de una historia de las ideas.

Comenzaré mi relato con la narración de los antecedentes del acusado, extraídos del informe pericial(3). N.N. nace en Pergamino, provincia de Buenos Aires, el 29 de febrero de 1875, en una familia de holgada situación y clase social elevada. Es el tercero de cinco hermanos. El mayor murió a los cuarenta y cinco años de tuberculosis pulmonar agravada por alcoholismo. Los dos hermanos menores también murieron, uno en la primera infancia a causa de una meningitis, el otro de tuberculosis. Tiene una hermana viva, sana, inteligente y normal. Su padre falleció aún joven, de una infección hepática Su abuelo materno y una de sus tías murieron de hemorragia cerebral, su abuela materna de diabetes, su madre de una infección neumónica, uno de sus tíos maternos es neurópata y una tía es alienada. Tal vez el lector se pregunte el

Rev. Asoc. Esp. Neuropsiq., 2001, vol XXI, n. ${ }^{\circ} 78$, pp. 113-123 
porqué de esta larga lista de enfermedades y decesos. Sucede que las normas generales para las pericias incluían -e incluyen- el estudio de los antecedentes hereditarios, familiares y personales. A partir de estos datos los peritos nos informan que es posible clasificar a todos los miembros de la familia materna de N.N. como "degenerados", siendo varios de ellos "degenerados superiores". Su degeneración se ha traducido por conductas anómalas -entre las que merece destacarse la "prodigalidad"-, acompañadas, sin embargo, de "intelectualidades superiores y brillantes"(4). Es necesario que nos detengamos aquí un momento, para explicar algunas teorías psicopatológicas en boga por aquella época y cuyo desconocimiento nos impidiría seguir el buen hilo del relato.

\section{En su Traité des dégénérescences} de 1857, Benedict Morel propone que el "tipo primitivo" de la raza humana es un hombre que acepta libremente y por su propia voluntad la ley moral, un hombre en el que el intelecto y la voluntad dominan sobre las pasiones. En la medida en que se va alejando de este tipo primitivo perfecto, la raza se va degenerando. El mal se hereda de generación en generación, aumentando en forma progresiva, produciendo un creciente deterioro físico y moral que lleva a la locura, la imbecilidad y finalmente a la eliminación natural(5). Esta concepción difiere de la idea lockeana, predominante en el siglo XVIII, de la alienación mental como desorden intelectual o "razonamiento erróneo"(6). Casi treinta años más tarde, V. Magnan retoma los desarrollos de Morel, pero reemplazando la interpreta- ción religiosa por una neurofisiológica. Inspirándose en los trabajos de Voisin, considera la degeneración como una desorganización del eje cerebro-espinal, destrucción o inhibición de ciertos centros cerebrales que quedan de este modo fuera del control y la voluntad consciente del sujeto(7). Divide a los degenerados en cuatro tipos: idiotas, imbéciles, débiles mentales y degenerados superiores. Estos últimos se caracterizan por ser sujetos aparentemente normales, incluso con una inteligencia muy por encima de la media, pero que se desequilibran ante una emoción, una enfermedad, un debilitamiento físico o una simple modificación fisiológica. Entonces se desvanece toda la armonía y surge el cortejo de defectos psicomorales(8). A diferencia de Morel, Magnan no postula un "tipo ideal" en el origen sino como la meta hacia la que la humanidad se dirige, homologando de este modo las ideas de evolución y progreso(9).

Retornemos pues a N.N. Muy inteligente y de temperamento nervioso, en el colegio se destacó entre los mejores promedios. Su sexualidad es normal. A pesar de que en su adolescencia fue muy fogoso, no llegó a masturbarse sino discretamente, porque "sus medios le permitieron bien pronto integrales satisfacciones"(10). Este hecho trajo como consecuencia que N.N. padeciera en varias ocasiones de blenorragia. Se recibió de médico en la Facultad de Ciencias Médicas de la Universidad de Buenos Aires en el año 1899 e ingresó como jefe de clínica del Dr. Escalier en el Hospital Rivadavia, permaneciendo en ese puesto hasta 1909 , año en que conoció a su futura esposa. 
Se casaron el 15 de julio de 1910 y se embarcaron para Europa el 28 del mismo mes. Curiosamente, el informe pericial no menciona nada más acerca de los avatares del viaje de bodas, de los que nos enteraremos más adelante por el informe judicial. Como veremos, esta omisión no es casual.

En 1911 muere la madre y a partir de 1912 comienzan los problemas económicos. El hermano mayor, que hasta la edad de treinta y cinco años había sido un sujeto ejemplar, a cargo de los bienes familiares desde el fallecimiento del padre, se vuelca de un día para el otro a la vida desordenada y viciosa, cayendo en un "alcoholismo inveterado" que finalmente lleva a la familia a la completa bancarrota. En mayo de 1916 N.N. se instala con su mujer en el pueblo de Weelwright, donde intenta ejercer su profesión. En abril de 1918 retorna a la capital "acompañando a su esposa moribunda". El 20 de abril de 1918 ingresa en el Hospicio de las Mercedes. Es sometido a un tratamiento brusco de desintoxicación morfínica, habitual en ese nosocomio según la versión del doctor.Jones, a cargo del servicio de clinoterapia. El otrora brillante y lleno de vida joven médico, ingresa deprimido, confuso, indiferente, apático. En su historia clínica se lee que no se observan estigmas físicos. Le faltan varios dientes superiores, es de estatura mediana, de piel pálida y fláccida, marcada por cicatrices, abcesos y nódulos -rastro de inyecciones recientes-, sobre todo en el brazo izquierdo, los dos muslos, flancos y glúteos. Padece de insomnio, ansiedad y angustia crecientes, náuseas, vómitos, anorexia, diarrea, astenia física marcada, temblores, estornudos y bostezos. Durante varios días permanece en ese estado, demandando insistentemente y en tono plañidero se le suministre morfina. Hacia el 29 de abril comienza a normalizar sus funciones. Ante el requerimiento médico, declara que comenzó a inyectarse morfina en 1912 a raiz de una fractura en la rodilla izquierda que sufrió en un accidente automovilístico.

Veamos los resultados del examen psicológico. No presenta alteraciones en el lenguaje articulado ni gráfico, pero en sus respuestas se percibe "el singular desmedro de una actividad cerebral que otrora fue hasta brillante"(11). Puede fijar la atención si se lo propone, pero se distrae fácilmente. Tiene problemas de memoria para evocar recuerdos recientes, sobre todo los relacionados con la última época de Weelwright. La percepción es clara y rápida. Llama la atención su "indiferentismo sentimental"(12) y su exagerado egoísmo. Se aprecia una marcada decadencia del sentido moral. Acá se hace necesario un nuevo paréntesis para introducir una breve referencia a las teorías subyacentes a la descripción misma. Dicen nuestros peritos: "Vemos afectarse primeramente el sentido moral, tanto más vulnerable cuanto que ha aparecido más tardíamente en la evolución funcional del cerebro, y luego, en mayor o menor intensidad, en el conjunto de los procesos psíquicos superiores"(13). Es esta la tesis jacksoniana(14), retomada por la escuela de Ribot y arribada por esta vía a las tierras del Plata, cuya mirada psicopatológica se dirige en esos años casi exclusivamente a los maestros franceses. 
Prosigamos con la explicación etiológica. A la funesta sombra de la degeneración hereditaria, se nos informa, se suman los efectos de la intoxicación crónica y la herencia neuropática. En esta familia el cerebro se presenta como constante locus minoris resistentiae(15). N.N. pertenece a ese tipo de degenerados inteligentes a los que Magnan denominó degenerados superiores, en los cuales, conjuntamente con facultades brillantes, coexisten lagunas o deficiencias en las demás esferas psíquicas: "extravagancias, debilidad de la voluntad y en general incapacidad para adaptarse a las condiciones normales para la lucha por la existencia"(16). Sigue una única y escueta referencia a la esposa, de quien se afirma que no pudo ayudarlo a controlar el vicio porque, al igual que él, era degenerada de constitución, débil de voluntad y presa también del "sutil veneno"(17). De esa forma, marido y mujer, como suele suceder entre los toxicómanos, se enviciaron mutuamente en su búsqueda de alcanzar los "paraísos artificiales" que no existen sino en la mente de los poetas(18). A medida que el sujeto repite la experiencia, cada vez con mayor frecuencia y a más altas dosis, se produce un embrutecimiento progresivo y la voluntad, débil desde un comienzo, queda mortalmente herida. Ya no puede reaccionar para liberarse del tóxico, pero se manifiesta imperiosa en la búsqueda del mismo. Poco a poco la personalidad se desintegra, el sujeto pierde el pudor, la dignidad, el sentido moral, la noción de la propia conveniencia, hasta llegar a una abulia completa y un increíble descuido de su persona y de lo que lo rodea. Cae en un estado de confusión mental que le impide valorar su situación, medir el alcance de sus actos o tener conciencia de lo que ocurre a su alrededor. Lo único que salvó al imputado de una muerte segura fue el tener una constitución física más fuerte que la de su cónyuge.

Sumando una más a las ya múltiples categorías psicopatológicas en que se ha encuadrado al acusado a lo largo del informe, se agrega ahora que el complejo sintomático que presenta corresponde a la neurosis que Janet denomino "psicastenia" $y$ otros han denominado neurastenia(19), ya que se observa en N.N astenia muscular, depresión física y cerebral, disminución de la espontaneidad y de la agilidad mental en los procesos ideativos, deficiencia volitiva y aplanamiento afectivo. A todos estos síntomas se suma la apetencia tóxica, que correspondería a las obsesiones que Janet caracteriza como parte del cuadro. Entre las conclusiones del informe puede leerse que "este conjunto sintomático somato-psíquico se prolongará todavía por un tiempo que no es posible determinar, dado el terreno degenerativo constitucional del sujeto"(20). Por consiguiente, los peritos consideran que "sin ser un alienado -demente en el concepto jurídico- el imputado presenta, actualmente, anomalías que atenúan su responsabilidad con relación a las prescripciones de la ley penal"(21) puesto que hay causas determinantes "más que suficientes" que pueden haber alterado su conducta regular habitual. Este informe es presentado al juez que entiende en el caso el 8 de agosto de 1918.

Pasemos ahora al auto judicial. Nos enteramos, en primer lugar, que 
durante el largo viaje de bodas -usual en esos años entre las clases adineradas- los esposos llevaron una vida "misteriosa", siempre encerrados, actitud que contrastaba fuertemente con el modo de ser alegre y expansivo que había caracterizado a la joven desposada hasta entonces. Según queda probado por las declaraciones de todos los testigos, nos dice el juez, antes de contraer enlace la víctima era "una persona completamente sana, de una educación esmerada, de un epíritu cultivado, de un carácter bondadoso, que cautivaba con su belleza física y moral, que revelaba una inocencia poco común y que no sólo no sufría de enfermedad alguna en su organismo físico, sino que no tenía vicios ni costumbres que hicieran sospechar siquiera que tuviera inclinación al uso del alcohol, de la morfina o de otros tóxicos"(22). Volvió del viaje totalmente cambiada, hasta el punto que "sólo aparentaba una déébil silueta de aquella bellísima niña, sana, alegre de cuerpo y alma, que pocos meses antes abandonara inocente su hogar, llena de ensueños, en busca de su ideal"(23). Al llegar aquí, el juez, como lo hicieran los peritos, alude a los famosos "paraísos artificiales" de Baudelaire, que en su opinión siempre concluyen sometiendo a quien los anhela a "su influencia venenosa".

Continúa relatando que al cambio físico correspondió la transformación mental. La joven se tornó nerviosa, malhumorada, irascible, aislándose cada vez más de sus amistades y su familia, repudiando incluso a su propia madre. Sólo la presencia de su esposo la calmaba y éste, se nos informa, no se separaba ni un instante de su lado. Pasaban cada vez más tiempo encerrados, descuidando sus obligaciones más elementales. Luego el relato se torna oscuro. Se habla de una misteriosa enfermedad que casi acabó con la vida de la infeliz esposa y de la que sólo se logró restablecerla "por todos los recursos de la ciencia y del cariño maternal"(24). El médico que la atendiera, amparándose en el secreto profesional, se negó a declarar las causas que la llevaron a tan grave crisis. ¿Se trató tal vez de una blenorragia? Como se mencionara en el informe pericial, el marido padeció este mal más de una vez. ¿O sería un dolor psíquico el que la puso al borde de la tumba? En todo caso, es seguro que se trató de algo vergonzante, puesto que el facultativo no quiso aclarar el diagnóstico. Revisando el informe con más atención, el nombre de este profesional nos resulta conocido. Descubrimos entonces que se trata del doctor Escalier, el mismo en cuyo servicio del Hospital Rivadavia N.N. trabajara durante diez años en tiempos más felices, al comienzo de su carrera profesional.

Luego, la caída es vertiginosa. Según las declaraciones de los vecinos, en los últimos tiempos la pareja ya no salía de la casa, comían lo que éstos, compadecidos, les llevaban y vivían solicitando préstamos por sumas insignificantes de dinero. Finalmente la salud de la desdichada esposa terminó de quebrantarse y el matrimonio viajó a Buenos Aires, donde ella falleció a los pocos días. Triste final para la triste historia de dos seres atormentados y de un extraño amor que se había prolongado a lo largo de ocho años. Según declara el doctor Viñas, testigo de la muerte, la "infinidad de lesiones 
anatómicas de la piel y la gran prostración general" no dejan lugar a dudas que lleg6 a ese estado "por el uso y abuso en forma desmedida de tóxicos por medio de inyecciones"(25). A esto agrega el juez que resulta evidente que las inyecciones se las aplicaba su marido "ocultamente y con plena conciencia del daño que ocasionaba"(26) y que la negativa de éste a efectuar una declaración confirma su culpabilidad. Destaca además que, como queda probado por la exposición de los hechos, es evidente que el acusado no comenzó a drogarse en 1912, como él afirma, sino mucho antes y que contagió a su mujer el vicio ya durante el viaje de bodas. Veamos, entonces, el alegato del Dr. Domínguez, juez de instrucción.

\section{La defensa social como debe ser.}

"El fin de la defensa social", afirma, "no es el castigo del culpable como una satisfacción por castigar, sino la necesidad de separar de su seno los elementos que la dañan"(27). Si se aceptara la irresponsabilidad legal de los viciosos, continúa, porque no tienen voluntad para dominar su pasión, se crearía una excepción de inmunidad legal con grave peligro para la sociedad, que no podría apartar de su seno a estos "elementos disolventes". Haremos ahora un último paréntesis, en referencia esta vez a las teorías penales. Sin pretender realizar un desarrollo que nos desviaría de nuestro interés principal, resulta necesario, sin embargo, aclarar mínimamente la concepción del derecho que aquí se pone en juego. Así como en psicopatología predominan las ideas provenientes de Francia, en críminología la mirada se vuelca hacia Italia. Siguiendo puntual- mente los desarrollos de Enrico Ferri, ya en los primeros años del siglo Ingenieros destaca que la criminología moderna, en contraposición a la escuela clásica de Beccaria, no presupone el libre albedrío (y por tanto la imputabilidad) del delincuente, sino que busca las causas de su acción en la constitución psíquica, en la herencia $y$ en las condiciones del ambiente en que éste se desenvuelve. No centra su interés en establecer la responsabilidad del criminal sino su grado de peligrosidad y su objetivo no es el castigo de un sujeto al que se presupone libre de elegir, sino la defensa del organismo social por medio de la segregación de los elementos que hacen peligrar su integridad(28). Para la época de nuestro informe, como puede apreciarse en el auto judicial, estas ideas continúan plenamente vigentes. Se considera que es obligación del Estado defender a los ciudadanos apartando de su seno a los criminales: "el orden y la seguridad de las sociedades dependen de esta función represiva que le está encomendada"(29). Sin embargo, en la práctica, la justicia se enfrenta con una paradoja en el caso de los toxicómanos: ¿cómo enviarlos a prisión si no son responsables de sus actos? ¿cómo recluirlos y obligarlos a curarse si su conducta viciosa atañe al mundo privado de las personas, en el cual un estado liberal no puede inmiscuirse? Estas contradicciones se ven reflejadas en los argumentos del juez. Puesto que la ley no prohibe el consumo de alcaloides, su postura intenta centrarse en demostrar que la conducta toxicómana, en este caso, ofende al orden y la moral pública y perjudica a un tercero(30), con lo cual quedaría legitimada su intervención. 
HISTORIA

Así, en total desacuerdo con el informe pericial, el doctor Domínguez pasa a enumerar sus razones: en primer lugar señala que el impulso irresistible, la falta de voluntad para sustraerse al tóxico, se comprende con respecto al propio sujeto, pero en ningún caso cuando se trata de calmar la apetencia de otro. Para continuar, afirma que la represióón debe ser más enérgica cuanto más elevada sea la posición social de quien cae en el vicio, ya que la responsabilidad legal es mayor a mayor educación. En este caso la responsabilidad es aún más alta por tratarse de un médico, que no sólo está habilitado para salvar a sus semejantes sino que tiene la obligación de hacerlo. Tercero y principal, dice, legitimar como resolución judicial los fundamentos del estudio médico sería autorizar legalmente la impunidad del vicio, "declarándose la justicia desarmada e impotente en su misión"(31). Aceptar estas teorías implicaría permitir a todos los anormales y desequilibrados que cometieran delitos y "como esas perturbaciones mentales ceden fácilmente a un tratamiento médico", los viciosos verían asegurada su irresponsabilidad legal sin perder su capacidad civil ni su libertad(32). Finalmente, expresa, es necesario recordar las palabras de Gilbert Ballot (sic)(33), quien dice que "cuando un tribunal tiene en cuenta la responsabilidad atenuada para rebajar la pena, hace mala justicia y mala protección social". Por todas estas razones, el doctor Domínguez declara a N.N responsable del delito de homicidio y ordena la prisión preventiva y el embargo de sus bienes por la suma de $50.000 \$$ (34). ¿Fue N.N. culpable de la muerte de su mujer? En caso contrario, ¿es justo condenar a un hombre por su "depravación moral" y no por ser culpable de un crimen? Pero nos enteramos por el informe pericial que el 3 de mayo de 1918 nuestro sujeto no es enviado a prisión, sino trasladado dentro del mismo Hospicio de las Mercedes, en calidad de detenido, al pabellón Lucio Meléndez, a cargo del doctor Helvio Fernández. Como tendremos oportunidad de comprobar, la historia no termina aquí.

El debate entre jueces y peritos por el tema de la toxicomanía se prolonga durante un largo período. En 1919 una ordenanza del Departamento Nacional de Higiene prohíbe la venta libre de medicamentos que contengan opiáceos o cocaína. Un año más tarde el diputado Capurro presenta un proyecto de ley en el que propone una reglamentación estricta de la importación, exportación, venta, prescripción y posesión de alcaloides. Esto suscita una acalorada reacción de la oposición. Se argumenta que una ley que interfiera con los "vicios privados" de las personas es contraria al artículo 19 de la Constitución Nacional(35) y se contrapone al proyecto liberal y laico de la Argentina moderna, que no es compatible con la imposición de valores morales a los ciudadanos. El diputado Bréard señala que penalizar la posesión de alcaloides sería tan absurdo como prohibir la posesión de armas para evitar el peligro del suicidio. $Y$ agrega que incriminar a alguien por la simple posesión de una sustancia supone atribuirle de antemano intenciones criminales(36).

En 1923 Leopoldo Bard presenta su proyecto -mencionado al comienzo de esta historia- que abre un debate similar 
al de 1920. Aunque no sugiere que se penalice el consumo, al demandar que los alcaloides y narcóticos sólo puedan comprarse bajo receta médica y según las dosis fijadas por la farmacopea, ubica en manos de los profesionales de la salud el monopolio de la decisión sobre lo que es malo o bueno para los particulares. En 1924 Juan M. Obarrio, Director del Instituto Frenopático y Médico del Servicio de Enfermedades Nerviosas del Hospital de Niños, redacta, a pedido de la Sociedad de Neurología y Psiquiatría, un "Proyecto de legislación sobre alienados, toxicómanos y pródigos"(37) que es presentado ante la Cámara de Diputados por el diputado Sussini. En relación a los toxicómanos, Obarrio propone la denuncia obligatoria, que debe ser presentada ante la Comisión Nacional de Alienados por el médico, la :. : : / la 0 el tutor. Se creará además un Registro Nacional de Alienados, Incapaces y Toxicómanos al que se podrá pedir informes sobre la capacidad de los inscriptos para disponer o no de sus bienes, contraer matrimonio y toda actividad que requiera la responsabilidad civil. Los toxicómanos no podrán contraer matrimonio hasta tres años después de su recuperación, "y siempre que un peritaje establezca que no hay en ellos degeneración mental"(38). Los toxicómanos extranjeros no podrán entrar al paíís ni permanecer en él si se comprueba que ya eran viciosos a su entrada. Se establecerá la internación obligatoria, acordada por el juez a pedido de la familia; el toxicómano internado "sólo podrá ser ser dado de alta con la autorización de la Comisión Nacional de Alienados, bajo la cual estará la fiscalización de los toxicómanos recluidos"(39). Al igual que el proyecto de Bard, este de Obarrio propone que los narcóticos no puedan ser vendidos sino en farmacia y bajo receta médica archivada, y sólo en las dosis autorizadas por la farmacopea(40).

En 1925 Bard demanda directamente que se penalice la tenencia de drogas. Esta vez cuenta como aliado con la policía y su propuesta encuentra el beneplácito de ambas Cámaras. La posesión "sin motivo legítimo", convertida en infracción penal, permite al cuerpo de policía intervenir en la vida privada de ciudadanos que no han dañado a otros(41). Sin embargo, tampoco ahora se llega a penalizar el consumo, o al toxicómano por el simple hecho de serlo. En 1928 Nerio Rojas, Carlos de Arenaza, Eusebio Gómez y Ricardo Seeber presentan al Senado un proyecto sobre "el estado peligroso sin delito", en el que quedan comnrendi!....'

nos, por considerarse que dejarlos in libertad representa un peligro para ellos mismos o para otros. Este proyecto caduca sin que se logre su sanción. En 1932 Juan Ramón Beltrán, profesor adjunto de Medicina Legal y de Psicología Experimental y Fisiológica en la Universidad de Buenos Aires, demanda la creación de un establecimiento oficial donde recluir a estos pacientes, puesto que al no existir tal organismo, muchos casos son derivados por el juez a la clínica que él dirige(42). En 1933 el Poder Ejecutivo presenta nuevamente al Senado el proyecto de Rojas, que lo rechaza argumentando que representa un arma peligrosa en manos de "policías bravas o de políticos inescrupulosos"(43).

En 1939, transcurridos veinte años desde los sucesos aquí narrados, el 
doctor Rogelio Carratalá, profesor titular de Toxicología de la Universidad de La Plata, todavía se lamenta de que "no le es posible a un juez, frente a características de peligrosidad de un toxicómano, disponer su reclusión en establecimiento conveniente"(44). En su opinión es imprescindible legalizar de una vez el tan controvertido estatuto de "estado peligroso sin delito" y el toxicómano debe ser internado en forma involutaria y obligado a llevar a cabo un tratamiento de cura en establecimientos médico-psicológicos especializados. Argumenta que, en última instancia, igual se los encierra en la cárcel o el manicomio, donde lo único que se consigue es que contagien a los demás su vicio. La legislación debería, además, contemplar un registro de alcaloidómanos y un ser- vicio de vigilancia psicológico-social proporcionado por el mismo establecimiento de cura, que fiscalizara la vigilancia de los ambientes de riesgo y el control periódico de los sujetos que ya hubieran salido curados(45). De este modo, nos explica Carratalá, se evitarían situaciones como aquella, por todos conocida, del médico morfinómano que habituó a su mujer llevándola a la muerte. Y por fin conocemos el final de la historia que ilustró este informe: "Este caso bien neto de contagio tóxico, que revelaba la existencia de un sujeto tan temible, no alienado, alcanzó la absolución del acusado ya que la muerte de la intoxicada se debió a la enfermedad intercurrente, y a que, por otra parte, el delito de aquél no se hallaba como figura delictiva en el Código Penal" (46). 


\section{BIBLIOGRAFÍA:}

1. Grendi, E. "Microanalisi e storia sociale". Quaderni Storici 1972,7:506-520.

2. Levi, G. "Sobre microhistoria". En: A.A.V.V. Formas de hacer Historia. Madrid. Alianza. 1994.

3. "La morfinomanía ante la ley penal". Informe pericial por los doctores H. Fernández, A. Jones, J. Brandam y E.Klapenbach. En: Revista de Criminologia, Psiquiatria y Medicina Legal. Año V. 1918. p-555-568.

4. Informe pericial. op.cit. p.556.

5. Morel, B.A. Traité des dégénérescences physiques, intellectuelles et morales de l'espèce humaine. Paris. Baillère. 1857. p.1-7.

6. Pick, D. Faces of degeneration. A European Disorder, 1848-1918. Cambridge University Press. 1989. p.51

7. Magnan, V. Leçons cliniques sur les maladies mentales. $2^{\circ}$ série. Les délires systématisés. Paris. Progrès médical. 1897. p.40-41.

8. Magnan, V. op.cit. p.93.

9. Vezzetti, H. La locura en la Argentina. Buenos Aires. Paidós. 1985.p.156.

10. Informe pericial. op.cit. p.557.

11. Informe pericial. op.cit. p.561.

12. Informe pericial. op.cit. p.562.

13. Informe pericial. op.cit. p.564.

14. Para Jackson (1834-1911) las funciones nerviosas superiores se fueron adquiriendo en forma jerarquizada, de las más simples a las más complejas, de las más organizadas a las menos organizadas, de las más automáticas a las más voluntarias. Siempre son las últimas en adquirirse las que controlan las precedentes, $y$, en forma inversa, la disolución de las funciones psíquicas sigue el camino opuesto. El trastorno implica un elemento negativo (supresión de la función o nivel alcanzado) y un elemento positivo (liberación e hiperfunción de los elementos contiguos a aquellos que fueron suprimidos o suspendidos. (Jackson, J.H. Selected Writings of John Hughlings Jackson. Edited by James Taylor. London. 1931.

15. Informe pericial. op.cit. p.564.

16. Informe pericial. op.cit. p.565.

17. ibid.

18. El comentario alude al libro de Charles Baudelaire, Les Paradis Artificiels, publicado en Francia en 1860, en el que el autor describe sus experiencias con opio y morfina.

19. El término "neurastenia" fue acuñado por el psiquiatra inglés Beard en 1879 para describir un cuadro caracterizado por cansancio cerebral, ideas obsesivas, borrascas de mal humor o cólera, fatiga permanente.(En: Bonnet, E. Medicina Legal. Bs.As. López Libreros. 1980. p. 1452).

"Psicastenia" es un término utilizado por primera vez por Janet en 1903. Caracteriza un tipo de neurosis en el que predominan las obsesiones, escrupulosidad mórbida hasta llegar a la fobia, timidez, vergüenza, duda, "sentimiento de incompletud", despersonalización, depresión. (Janet, P. Les obsessions et la psychastenie. Paris. Alcan. 1919).

20. Informe pericial. op.cit. p.567.

21. Informe pericial. op.cit. p.568. Las cursivas son del original.

22. Citado en: Bard, L. Los peligros de la Toxicomania. Proyecto de Ley para la represión del abuso de los alcaloides. Buenos Aires. Talleres Gráficos Argentinos de J.J.Rosso y Cía. 1923. p.18. 
HISTORIA

23. Citado en: Bard, L. op.cit. p.19.

24. Citado en Bard, L. op.cit. p.20.

25. Citado en Bard, L. op.cit. p.21.

26. ibid.

27. Citado en: Bard, L. op.cit. p.26.

28. Ingenieros, J. "Valor de la Psicopatología en la Antropología Criminal". En: Archivos de Criminologia, Medicina Legal y Psiquiatría. 1902. p.355.

29. Drago, L.M. Los hombres de presa. Bs.As. La Cultura Argentina. 1921. p.76.

30. Ver el artículo 19 de la Constitución Nacional, citado más abajo (Cita n³3).

31. ibid.

32. Citado en: Bard, L. op.cit. p.27.

33. Se refiere a Gilbert Ballet, quien fue alumno de Charcot y le sucedió en el cargo en La Salpêtrière (luego de Ball y Joffroy). En 1904 dirige la publicación del Traité de pathologie mentale, en el que colaboran Cotard, Arnaud, Ball, Chaslin y Séglas entre otros.

34. Citado en: Bard, L. op.cit. p.28.

35. "Las acciones privadas de los hombres, que de ningún modo ofendan al orden y a la moral pública, ni perjudiquen a un tercero, están sólo reservadas a Dios y exentas de la autoridad de los magistrados. Ningún habitante de la Nación será obligado a hacer lo que no manda la ley ni privado de lo que ella no prohibe."

36. Aureano, G. "La construction politique du toxicomane dans l'Argentine post-autoritaire. Un cas de citoyenneté à basse intensité". Tesis de Doctorado en Ciencias Políticas, presentada en la Facultad de Ciencias Políticas de la Universidad de Montreal. Aprobada el 23 de abril de 1998. Bajada de Internet: www.pum.umontreal.ca/Theses. (sin números de página).

37. Obarrio, J.M. "Proyecto de legislacióón sobre alienados, toxicómanos y pródigos". Rev. de Criminologia, Psiquiatria y Medicina Legal. Año XI. 1924. p.139-171.

38. Obarrio, J.M. op.cit. p.147.

39. Obarrio, J.M. op.cit. p.150.

40. Obarrio, J.M. op.cit. p.170.

41. Aureano, G. op.cit. (sin número de página)

42. Beltrán, J.R. “La responsabilidad de los toxicómanos”. En: Revista de Criminología, Psiquiatria y Medicina Legal. Año XIX. 1932. p.193.

43. Carratalá, R. "Toxicomanía y delincuencia". Trabajo presentado en el $1^{\circ}$ Congreso Latinoamericano de Criminología (Buenos Aires, 25-31 julio 1938), publicado en la Revista de Psiquiatria y Criminología. Tomo IV. 1939. p.103-114.

44. Carratalá, R. op.cit. p.113.

45. Carratalá, R. op.cit. p.114.

46. Carratalá, R. op.cit. p.112.

\section{* Psicóloga}

Universidad Nacional de Mar del Plata

Dirección particular: Saavedra 264. (7600) Mar del Plata. Buenos Aires. Argentina.

E-mail: paweis@mdp.edu.ar

Fecha de recepción: 23-10-00 